\title{
Using a Socioecological Approach to Examine Participation in Sport and Physical Activity Among Rural Adolescent Girls
}

\author{
Meghan M. Casey \\ Rochelle M. Eime \\ Warren R. Payne \\ Jack T. Harvey \\ University of Ballarat, Mt. Helen, Victoria, Australia
}

\begin{abstract}
Adolescence is a critical time for developing lifelong healthy behaviors, including active lifestyles. Participation in sport and physical activity, however, declines during adolescence, and few studies have comprehensively identified why, particularly among rural girls. This article identifies a range of independent and interacting factors that influence sport and physical activity participation of rural adolescent girls. The socioecological model of health was used to guide four focus group discussions with Grade 7 girls $(n=34)$. The results showed that adolescent girls were positively influenced when sports or physical activities were fun, when they involved being with friends, and when they were supported by families and teachers through role modeling and positive feedback. A range of intrapersonal and organizational factors affected perceived self-competence, particularly the coeducational nature of school physical education classes and peer teasing, which supported social comparisons of skill level. In promoting sport and physical activity to rural adolescent girls, focus must be directed on developmentally appropriate activities that are fun, offering opportunities for single-sex classes, and generating cultural changes that encourage noncompetitive and selfreferencing activities.
\end{abstract}

Keywords: adolescents, female; exercise; health behavior; obesity; physical activity; qualitative methods, general; youth

$\mathrm{B}$ eing overweight and obese are major health problems for children, adolescents, and adults, and there is widespread concern that declining physical activity levels are contributing to this (Sparling, Owen, Lambert, \& Haskell, 2000; Warburton, Nicol, \& Bedin, 2006). For adolescent youth there are generally three main opportunities for physical activity: physical education classes, organized sports, and unorganized or unstructured activities such as walking. Participation in physical activity, however, appears to decline with age (Brady, 2004; Pate, Dowda, O'Neill, \& Ward, 2007), and particularly during adolescence (Lubans, Sylva, \& Morgan, 2007; Scheerder,

\footnotetext{
Authors' Note: Drs. Caroline Symons and Melinda Craike are acknowledged for their contribution to the development of the interview questions and analysis themes. This study was funded by the Sport and Recreation Division of the Department of Planning and Community Development, and the Victorian Health Promotion Foundation (VicHealth).
}

Vanreusel, Taks, \& Renson, 2005; Zick, Smith, Brown, Fan, \& Kowaleski-Jones, 2007). In particular, adolescent girls seem to be less active than boys (Sanchez, et al., 2007), and have a higher sport-club withdrawal rate (Vilhjalmsson \& Kristjansdottir, 2003).

Adolescence is widely recognized as a difficult and stressful time for young people because of rapid changes in body image and self-esteem, as well as changes in their peer groups and school environment as they transition from primary to secondary school and later into tertiary education or the workforce (Eccles, Midgley, Wigfield, \& Buchanan, 1993; Schulenberg, Maggs, \& Hurrelmann, 1997). Some of these changes have been shown to negatively affect physical activity participation rates among adolescent girls (Garcia, Pender, Antonakos, \& Ronis, 1998; Zick et al., 2007). Considering that adolescent physical activity has been suggested to be positively associated with adult physical activity levels (Hallal, Victoria, Azevedo, \& Wells, 2006; Perkins, Jacobs, 
Barber, \& Eccles, 2004), adolescence is a critical time for developing lifelong physical activity behaviors that not only reduce the health consequence of inactivity during adolescence but also adulthood, especially among girls ( $\mathrm{Vu}$, Murrie, Gonzalez, \& Jobe, 2006).

The declining level of physical activity among adolescents has led researchers to identify a range of influences that affect participation in physical activity. Under the socioecological model of health, these influences are generally categorized as either intrapersonal (e.g., cognitions/emotions), interpersonal (e.g., family and friends), or organizational or environmental factors (e.g., neighborhood design; McLeroy, Bibeau, Steckler, \& Glanz, 1988; Sallis \& Owen, 2002). A number of independent relationships have been identified at each of these levels. For example, there is some evidence that adolescents with high perceived competence in the performance of motor skills participate in more physical activity (intrapersonal; Trew, Scully, Kremer, \& Ogle, 1999), and that parents who model their physical activity behavior or provide access to physical activities can influence the physical activity levels of their children (interpersonal; Dwyer et al., 2006; Kalakanis, Goldfield, Paluch, \& Epstein, 2001). Others have suggested that negative experiences during school physical education can lower interest and involvement in subsequent leisure-time physical activity (organizational; Ennis, 1996; Stewart \& Taylor, 2000), and the availability, cost, and proximity to recreation facilities or walking and bicycling trails influence regular participation in physical activity (environmental; Giles-Corti \& Donovan, 2002; GordonLarsen, Nelson, Page, \& Popkin, 2006; Humbert et al., 2006).

Many independent physical activity studies (Allender, Cowburn, \& Foster, 2006; Humbert et al., 2008) can be linked to the socioecological model; however, they do not provide a comprehensive overview to examine the interaction of the key elements of the socioecological model of health specifically for adolescent girls. To build the theoretical evidence base for informing policy makers, Allender et al. (2006) called for more qualitative and quantitative research to understand motivations and barriers to participation in physical activity. Furthermore, few studies have examined physical activity participation patterns or barriers to participation of adolescent youth in regional settings.

Examination of the influences on sport and physical activity participation by rural adolescent girls is important, considering that the health status of rural residents is generally poorer than those living in metropolitan areas (Australian Institute of Health and Welfare, 2003), and there is some evidence that rural residents are less physically active than their metropolitan counterparts (Martin et al., 2005; Parks, Housemann, \& Brownson, 2003). The rural setting is also important from the perspective that regional areas often have poorer access to services and facilities because of the effect of locational disadvantage (Dixon \& Welch, 2000), and research has suggested that proximity to physical activity facilities is a determinant of physical activity behavior (Gordon-Larsen et al., 2006).

The purpose of this study was to use the socioecological model of health to identify a range of independent and interacting factor-individual, intrapersonal, organizational, and environmental - that influence participation in sports and/or physical activity by adolescent girls within a rural context. Specifically, the study was conducted in Victoria, Australia, and the findings are of interest in countries where organized sports is delivered through school and/or community club settings.

\section{Method}

\section{Participants}

The sampling frame consisted of a list of all secondary schools (years 7 to 12; approximate age range 12 to 18 years), including government, independent, and Catholic schools within the Australian state of Victoria. First, a file of postal codes and local government areas (LGAs) was used to designate each school as either rural or metropolitan. Rural schools were defined as being outside the 31 LGAs considered to constitute metropolitan Melbourne (Department of Planning and Community Development, 2008). These schools were then sorted randomly, and a sample of four schools were checked for representativeness by plotting the sequence of Socio-Economic Indexes for Area (SEIFA) values, an index of relative socioeconomic disadvantage (Australian Bureau of Statistics, 2008). Finally, the geographical distribution of the sample was examined using the Accessibility and Remoteness Index of Australia (ARIA ${ }^{+}$) and the Australian Standard Geographical Classification (ASGC) Remoteness Areas classification. ARIA ${ }^{+}$ index values are based on road distance from a locality to the closest urban center with a population of at least 5,000 people (Australian Institute of Health and 
Table 1

Summary of Community Demographics

\begin{tabular}{|c|c|c|c|c|c|c|c|}
\hline Region & $\begin{array}{c}\text { Town } \\
\text { population }^{\mathrm{a}}\end{array}$ & $\begin{array}{l}\text { Distance from } \\
\text { capital city }\end{array}$ & $\begin{array}{l}\text { Distance from } \\
\text { closest Victorian } \\
\text { regional center }{ }^{\mathrm{b}}\end{array}$ & Land use & SEIFA & $\begin{array}{l}\text { ARIA+ (ASGC } \\
\text { classification) }\end{array}$ & $\begin{array}{l}\text { Number of } \\
\text { focus group } \\
\text { participants }\end{array}$ \\
\hline $\begin{array}{l}\text { West } \\
\text { Gippsland }\end{array}$ & 12,943 & $105 \mathrm{kms}$ & $\mathrm{n} / \mathrm{a}$ & $\begin{array}{l}\text { Dairy farming, timber, } \\
\text { industry, power station }\end{array}$ & 990 & $\begin{array}{l}0.81 \text { (Inner }^{-} \\
\text {regional) }\end{array}$ & $8(23.5 \%)$ \\
\hline Northeast & 10,035 & $213 \mathrm{kms}$ & $61 \mathrm{kms}$ & $\begin{array}{l}\text { Farming (fruit, vegetables, } \\
\text { dairy, crops, beef, wool, } \\
\text { lamb) }\end{array}$ & 993 & $\begin{array}{r}1.31 \text { (Inner } \\
\text { regional) }\end{array}$ & $5(14.7 \%)$ \\
\hline Wimmera & 6,035 & $237 \mathrm{kms}$ & $124 \mathrm{kms}$ & $\begin{array}{l}\text { Farming (grain, wool, } \\
\text { lamb) }\end{array}$ & 933 & $\begin{array}{r}1.92(\text { Inner } \\
\text { regional })\end{array}$ & $11(32.4 \%)$ \\
\hline $\begin{array}{l}\text { West } \\
\text { Wimmera }\end{array}$ & 1,000 & $415 \mathrm{kms}$ & $302 \mathrm{kms}$ & $\begin{array}{l}\text { Farming (grain, wool, } \\
\text { lamb) }\end{array}$ & 936 & $\begin{array}{l}5.69\left(^{(O u t e r}\right. \\
\quad \text { regional })^{d}\end{array}$ & $10(29.4 \%)$ \\
\hline
\end{tabular}

Note. Populations and distances are approximate.

${ }^{\text {a }}$ Data from 2006 ABS Census for state suburb (Australian Bureau of Statistics, 2006)

${ }^{\mathrm{b}}$ Victorian regional center defined using Rural, Remote, and Metropolitan Area (RRMA) Classification (Australian Institute of Health and Welfare, 2004), whereby the largest regional center is classified as a population of 25,000 to 99,999. RRMA is an index of remoteness that is based on distance to service centers, as well as a measure of distance from other people.

${ }^{c}$ Inner Regional Australia: Some restrictions to accessibility of some goods, services, and opportunities for social interaction

${ }^{d}$ Outer Regional Australia: Significantly restricted accessibility of goods, services, and opportunities for social interaction

Welfare, 2004). The ASGC Remoteness Areas classification is derived from $\mathrm{ARIA}^{+}$scores (Australian Institute of Health and Welfare, 2004). The communities in which the schools were located are described in Table 1. Based on the above classifications all schools were located in rural communities, which were separated by large distances to services and facilities and where land is primarily used for farming.

\section{Procedure}

Within each secondary school, physical education teachers were recruited and provided with information packets to distribute to all Grade 7 girls. The packets contained plain-language statements and child and parent consent forms. Girls who returned their consent forms and were present on the day of the scheduled focus group participated. These girls had recently transferred from primary (elementary) to secondary school. Focus groups were held in each of the four schools, in classrooms, during school hours. Each focus group was approximately 60 minutes in length and involved between five and 11 Grade 7 girls, aged 12 to 13 years $(n=34)$. Prior to the focus group discussion, participants were asked to complete a short form that asked about their demographics, including age, town of residence, country of birth, language spoken at home, and parent/guardian occupation. Participants were also asked to briefly describe their participation in sports and physical activities: What activities do you do for fun? and What, if any, physical activity or sport do you participate in on a regular basis (i.e., at least once per week)?

The socioecological model of health was used to develop the semistructured interview guide, and has been used previously in similar studies (Eime, Payne, Casey, \& Harvey, in press; Holt et al., 2008). The socioecological model of health was deemed appropriate as it provided an opportunity for in-depth analysis of the complexities of physical activity behavior and the examination of physical activity in the context of the individual's life, rather than being artificially separated from other factors in their life (Miles \& Huberman, 1994). At the commencement of the focus group discussion, participants were asked to identify the types of activities they participate in during their spare time, and then asked the reasons why they chose to participate in these activities. A number of subquestions designed around the socioecological model were used to guide the open-ended question. Some examples include, What do you enjoy or dislike about sport/physical activity? (intrapersonal); How were you influenced by parents/teachers/siblings/ friends to participate in sport/physical activity? (interpersonal); Do you participate in sport/physical activity because of your experiences in school? (organizational); and How does living in the country affect your participation? (environment). Interviews 
were audiotaped and later transcribed verbatim and de-identified.

Ethics approval was obtained from the University Human Research Ethics Committee, the Department of Education, and the Catholic Education Office.

\section{Data Analysis}

Data analysis was an ongoing process, and the research team met several times to formulate themes and create diagrams, as suggested by Bogdan and Biklen (1992), to explore different ways of putting data together. The interview transcripts were read and reread between two researchers, who then collaboratively generated the coding tree containing potential themes and subthemes. The transcript content and coding themes were then discussed with independent researchers to validate the themes and to increase the rigor of the analysis (Miles \& Huberman, 1994). The transcripts were then coded by the first author, sentence by sentence, according to the themes identified using NVivo Version 7 (QSR International, 2007). During this process, the researcher used a constant comparison technique and continually referred to previously coded comments for comparison. Diagrams using the socioecological model were generated to show common, as well as unexpected, responses. The socioecological model provided a context for examining the range of factors that influence physical activity and sport participation of adolescent girls.

\section{Results}

\section{Participant Demographics}

All participants were aged between 12 and 13 years ( $n=15,44.1 \%$; and $n=19,55.9 \%$, respectively) and lived in rural Victorian communities situated in Wimmera, West Wimmera, West Gippsland, or northeast regions of Victoria (see Table 1). These communities were classified by $\mathrm{ARIA}^{+}$as being "inner regional" (some restrictions to accessibility of some goods, services, and opportunities for social interaction) and "outer regional" (significantly restricted accessibility of goods, services, and opportunities for social interaction). The SEIFA score for these communities ranged from 933 to 960 (for Victoria, 826 to 1218). Two participants were born in countries other than Australia; however, they were both from Englishspeaking nations; thus all participants lived in households where only English was spoken. Being from rural communities, $23.5 \%$ of the participants had parents who were farmers.

Activities that the participants reported taking part in for fun were sports such as netball and swimming ( $n=22 ; 64.7 \%$ ); passive activities like listening to music and reading $(n=19 ; 55.9 \%)$; recreational activities including bike riding and horseback riding $(n=18 ; 52.9 \%)$; and social activities that involved being with friends $(n=12 ; 35.3 \%)$. The most common sports or physical activities that participants reported taking part in at least once a week were netball $(n=15 ; 44.1 \%)$ and basketball $(n=12 ; 35.3 \%)$, followed by tennis $(n=8 ; 23.5 \%)$, walking or running $(n=8 ; 23.5 \%)$, dance $(n=3 ; 8.8 \%)$, and swimming $(n=3 ; 8.8 \%)$. Three participants stated that they did not regularly participate in any sports or physical activities and another only reported regular participation in school physical education.

\section{Intrapersonal Factors}

Two main themes emerged from the focus group discussions in relation to intrapersonal factors: sport and physical activity goals were described as either task-goal orientations (e.g., focus on task and/or personal improvement) or outcome-goal orientations (e.g., focus on rewards and/or comparing self to others). The participants primarily reported participating in sport and physical activity for outcome goals such as health benefits (i.e., "a way to keep fit and healthy") and social benefits (i.e., "hang out with your friends;" "meet other people"). Some participants also reported task goals like improving their skill level (i.e., "gradually build up skills ... . and try new things") and increasing their enjoyment (i.e., "have some fun"). An important factor that was discussed by most participants was the need for sport and physical activity to be fun, and fun was often associated with being able to participate with their friends.

Participation in sport and physical activity was enhanced when participants' perceived self-competence was high. In particular, the participants in this study felt that the attainment of outcome goals such as competition success and peer recognition increased their self-competence, enjoyment, and the likelihood of maintaining their participation:

I reckon you feel better at a sport when you succeed in it, you want to keep going because you know that people like you and they appreciate you. (northeast Victoria)

Say you think you are going to do really bad [in sport/ physical activity] and then you come really good, that 
boosts your self-esteem and you want to do that because you think, "I am actually good at it." (northeast Victoria)

A lack of success or lack of peer recognition, however, were deterrents to participating in sport and physical activity, particularly on sporting teams when participants felt pressure to perform well or did not believe that they had the "right" type of skills:

If you are in a team with all the good people, you have to make sure that you do everything right, there's always pressure. (northeast Victoria)

Like some of them are real fast and you think, "God I wish I could be like that." And you don't want to go in an event because you know she will win. (West Gippsland)

Motivation to participate in team sports was also affected by the notion that there was a "good team" and a "bad team" which were related to skill level. One group of participants discussed the benefits of matching teams for skill level; however, they also felt that the "bad team" was undesirable and affected their confidence to participate in sports:

I think if you are in a team with all bad people then you would feel more confident because you know they are no better than you and if you are in a team with people better than you, you just feel like, "Oh my God, I will stuff it up if you do this or do that," and you want to go off . . . [however] you don't feel as confident if they decided that this is the good team and you're in the bad team ... you get put in the bad team and then it makes you feel bad. (northeast Victoria)

An alternative option to competing against other adolescent girls for a place in the good team was to choose a sport that was not as popular. For example, netball was highlighted as a popular sport, and gaining a place in the team was competitive. On the other hand, football (soccer) was mentioned as a less-popular sport girls could play, other than netball, and the girls perceived that it did not require a high skill level to participate. Other factors reported to influence participation in sports or physical activities at the intrapersonal level were injury, boredom, and involvement in technology-related activities.

\section{Interpersonal Factors}

The interpersonal factors that were predominantly discussed related to family, friends, and peers. The family, including parents and siblings, were important determinants of the girls' participation in sport or physical activity. In particular, family members who were active participants in sports or physical activities facilitated participation because they encouraged and provided opportunities for the girls to be active:

My brother is a pretty active guy so whenever he wants to go for a bike ride I always go with him. (West Wimmera)

It's good if your parents are sporty because they know what you feel like and they say they will drive you. (northeast Victoria)

Conversely, some participants reported that they were unable to access opportunities for sports or physical activities because parents were "unwilling to drive;" "It depends if Mum was working on the weekend;" or "Mum was too unwell to drive" (West Wimmeria).

As discussed previously, being with friends was generally associated with having fun. Friends were also identified as an important support network that encouraged participation in sports and physical activities, and provided opportunities to socialize:

I reckon if you go walking with someone it gives you motivation to actually get up because you know someone is waiting for you. (northeast Victoria)

The participants perceived that their enjoyment and self-competence diminished when their peers teased them. Peers did not necessarily provide a supportive environment for participation in sport or physical activity, particularly in the school setting or when engaged in coeducational physical education classes. Peer teasing was primarily discussed in terms of body image, academic performance, and competence. It was suggested that boys, in particular, intimidated and embarrassed girls, especially girls who were overweight or lacked motor skills. Boys were also thought to make fun of what girls wore and excluded girls from games or activities because of their low motor skill level. The following statements demonstrate the perceptions relating to peer teasing:

Say you get good grades like A+; they say you can't play football or you can't play sport because you're a nerd. (northeast Victoria)

I hate it when people give you a hard time about not being good at a certain sport. (West Wimmera) 
Some kids are just so good at sport and they don't think that the people who aren't good at sports should even try. They think they should just stand there. (northeast Victoria)

Yes they're [the inactive girls] getting called fat or something. (West Gippsland)

Participants also perceived that their peers not only ridiculed them when they lacked the requisite motor skills and were "not good at sport," but also when they were competent players: "Oh my god she is such a tomboy, don't play with her" (northeast Victoria). Some participants also perceived that their peers were too competitive and rough, which likely limited their participation. For example:

I would hate to be on the basketball team anyway because you get tackled and there's big girls that go for you. (West Gippsland)

Some teams are really competitive and all they want to do is win, but some girls want to have fun. (West Gippsland)

\section{Organization/Environment}

Within the environment, several issues were identified relating to the schools, sport clubs, and rural settings. The school environment was perceived to provide both positive and negative influences on the girls' participation in sport and physical activity. The school setting was thought to be supportive when teachers provided positive feedback to students (e.g., "One of the teachers said I was really good at netball at school and that's when I tried to get into netball;" northeast Victoria); when teachers acted as physically active role models; and when opportunities were provided to learn new skills. Similarly, the school environment was perceived to negatively affect girls' participation when girls received negative feedback from teachers (e.g., "I don't like it when sports teachers push you to do too much. . . . I don't like it when they say, 'Do this, do that,' and when you can't do it they yell at you and say, "You are just not trying hard enough;" northeast Victoria), and when physical education classes were coeducational. Many of the girls discussed the desire to have single-sex classes during school physical education, primarily because boys were considered to be too rough and/or too competitive, teased them, or excluded the girls from activities:

There should be more boys' classes and girls' classes because it makes you feel more comfortable and you would make more effort and all the girls would encourage each other. (West Gippsland)

There should be girls' and boys' groups because some girls might get embarrassed, if they want to do it. (West Gippsland)

Girls in two of the focus groups also identified male physical education teachers as a potential negative influence on their participation in school sports and physical education. The girls felt that male teachers were too competitive, sided with the boys, and were not as sensitive as female teachers:

Male [teachers] just make you think that you just don't want to do it, and I think the females are more sensitive and if you don't get something right they won't yell at you and they tell you what you did wrong. (Northeast Victoria)

I like our teacher, she doesn't pick the side with the boys all the time. She asks us our opinion of what we want to do. (West Gippsland)

Community or club sports were identified as being even more competitive and exclusive than schoolbased sports, particularly by the girls who were perceived to lack competence in the particular sport:

It gets more competitive out of school and people start really relying on getting the best squad team ... and if you're not good at the sport, if you're not any good at sports you can't play because no one will pick you. (northeast Victoria)

For the squad tryouts they only tell the people who they want to try out for the squad team. They don't tell the people who aren't so good because they don't want everyone to turn up. (northeast Victoria)

Finally, a number of discussion points were raised about how the rural setting affected participation. In general, the rural communities were perceived to restrict the girls' participation in sport and physical activity primarily because there was a lack of opportunities (e.g., "In a little town it is kind of hard because there are not many teams;" northeast Victoria); travel distances were too far to regularly access sports (e.g., "I live too far away to play extra sport;" West Gippsland); and rural towns were perceived to not have enough players to fill teams. Some focus group participants also felt that playing sports in rural areas was different compared to the metropolitan cities. In one case, it was because there were limited opportunities to meet new people, as one participant described: 
It would be a bit different in Melbourne [Victorian capital city] because you might play netball with one person and then play tennis with another person. Here you kind of play netball, tennis, and basketball with the same person. (West Wimmera)

In another case, it was felt that there was a community expectation in rural communities for girls to conform to a sport "norm." In this specific example, the participant referred to the sport of netball, which is the dominant sport played by Australian women:

You should really play netball because every girl should be really girly and play netball. (northeast Victoria)

The benefit of living in rural areas was that "there is more encouragement and more opportunities when you are in a country town because you know the people and they know you, and if you are not good at sport then they can encourage you" (northeast Victoria). Another group of participants felt that sport was "nice here because you have all your friends to do sport," and "Here on the farm there is a lot of space to do your activity" (West Wimmera). Another group agreed that they had greater access to free play, as demonstrated by the following exchange:

Interviewer: Do you think girls in the city have more opportunities than you?

Girl 1: No, not really.

Girl 2: They can't run around and stuff.

Girl 3: People say its better, even if the girls in the city if they do netball or something, but we have land so we can do stuff at home. (West Gippsland)

\section{Discussion}

The socioecological model of health was used in this study to identify a range of independent and interacting factors that influence sport and physical activity behavior of adolescent girls in rural Victoria. It is important to note that there have been few studies that have examined the interaction of the key elements of the socioecological model of health either comprehensively among youth or within a rural context (Allender et al., 2006; Eime et al., in press; Humbert et al., 2008). The results of this study offer qualitative evidence of the interplay of intrapersonal factors, the interpersonal environment, and the organizational environment on rural adolescent girls' participation in sports and physical activity.
Adolescent girls who have commenced Grade 7 are particularly vulnerable to declining levels of physical activity as they begin to experience changes associated with their body image and self-esteem (intrapersonal), in their peer groups and support networks (interpersonal), and their school environment (organization/environment; Garcia et al., 1998). This period, therefore, is an increasingly important one for the promotion of physical activity by practitioners, policy makers, physical education teachers, and the like to encourage long-term participation among adolescents - particularly as their rates of participation in physical activity decline with age (Brady, 2004; Pate et al., 2007).

In this study we found that adolescent girls were generally focused on outcome goals such as health and social benefits when participating in sport and physical activity, and that family and friends provided important social structure. Specifically, participation in sport and physical activity was positively influenced when activities were fun, when they involved being with friends, and when they were supported by families and teachers through role modeling and positive feedback. Participation was negatively influenced by a perceived lack of self-competence, which was affected by a range of social (e.g., friends) and organizational (e.g., coeducational nature of physical education) factors. In addition, there was a perception that girls in rural communities were limited in their physical activity choices, and their remoteness influenced their ability to access sporting facilities. These integrated findings are largely consistent with previous research, which generally examined the elements of the socioecological model independently of one another. For example, friends and family have been suggested to be important influences for adolescents (Garcia et al., 1995; Humbert et al., 2008; Kientzler, 1999; Scheerder et al., 2005; Thompson, Humbert, \& Mirwald, 2003); self-efficacy (Allison, Dwyer, \& Makin, 1999) and feeling inadequate or incompetent have been identified as barriers to physical activity (Harris, 1993; Sleap \& Wormald, 2001; Taylor, Legrand, \& Newton, 1999); and perceived environmental characteristics such as the presence of physical activity facilities and sidewalks have been positively associated with physical activity behavior (Duncan, Spence, \& Mummery, 2005).

The results of this study extend the literature by conceptualizing the intrapersonal, interpersonal, organizational, and environmental factors within competence motivation theory (Weiss \& Chaumeton, 1992; 
Figure 1

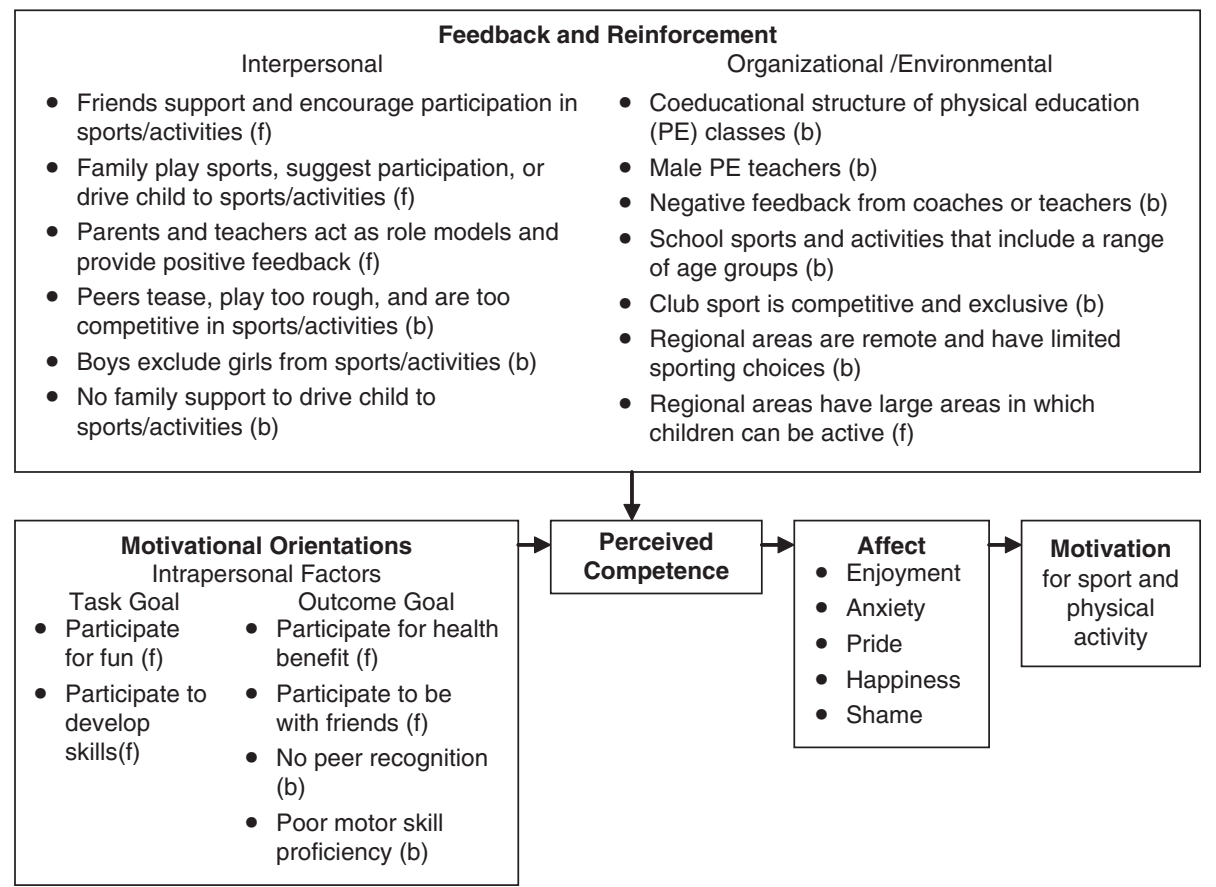

see Figure 1). A considerable amount of research has demonstrated the link between competence and motivation, whereby individuals with perceived high competence and control over the learning and performance of skills increase their enjoyment, pride, and happiness, and these positive affective states in turn lead to motivation for the activity (Weinberg \& Gould, 2003; Weiss, 1993; Wong, 1995). The use of competence motivation theory was considered appropriate, as a common finding was that individual, interpersonal, organizational, and environmental factors interacted with perceived competence to influence participation in sport and physical activity. In this study, discussions that were centered on perceived self-competence frequently involved insecurities about poor performance and skill level, which were intensified by gendered influences from their peers and the coeducational structure of school physical education. This might result in these adolescent girls focusing on shame and worry, whereby they have a high motivation to avoid failure, and thus seek to avoid sports and physical activities that highlight their lack of motor skills and attract negative attention. Adolescence is widely recognized as a difficult and stressful time for young people, with peer influence and the desire to "fit in" especially important at this time (Burns, Maycock, Cross, \& Brown, 2008; Norton,
Lindrooth, \& Ennet, 1998). In the following section we discuss how gendered interpersonal and organizational factors such as the peer group affect perceived self-competence.

The adolescent girls were motivated by friends to participate in sport or physical activity because it provided an opportunity to have fun, be with their friends, and meet new friends. This is consistent with previous findings (Garcia et al., 1995; Kientzler, 1999; Scheerder et al., 2005), and is particularly true among Grade 7 and 8 students, who are more likely to be motivated to engage in physical activity to make new friends, compared to older students who identified friends as being influential in their decision to maintain their participation (Humbert et al., 2008). Peers in general, however, were often described by participants as creating a social environment that lacked positive feedback and reinforcement because of peer teasing, which supported the adolescents in making comparisons in their level of motor skill proficiency.

Teasing was a commonly identified problem, particularly in the school environment. The girls in this study reported experiences and observations of peer teasing related to sport or physical activity in terms of body image, academic performance, and competence, all of which reduced girls' confidence to participate. Boys, in particular, were identified as instigators of 
peer teasing for both physically active and inactive girls. It also appeared that girls were caught between gendered stereotypes in their motor skill proficiencybetween being too good (e.g., a "tomboy") and not being good enough. Teasing combines elements of aggression, humor, and ambiguity (Shapiro, Baumeister, \& Kessler, 1991), and is often directed at the victim's physical appearance (Mooney, Creeser, \& Blatchford, 1991) — especially body weight status (Cash, 1995; Thompson, Cattarin, Fowler, \& Fisher, 1995). Criticism of body weight while engaging in physical activity has been linked to lower rates of physical activity and reduced sports enjoyment (Faith, Leone, Ayers, Heo, \& Pietrobelli, 2002). Teasing has also been directed at the victim's athletic ability, making him or her feel self-conscious, and therefore, causing them to avoid future participation in physical activities (Bauer, Yang, \& Austin, 2004; Vu et al., 2006). In a qualitative study that involved both students and staff in focus group discussions in the New England region of America, experiences of peer teasing were major barriers for students - particularly girls - to be physically active during physical education classes, on sports teams, and before and after school (Bauer et al., 2004). Both adolescent boys and girls might be subjected to peer teasing regarding their lack of motor skill proficiency; however, boys might not experience to the same extent (if at all) criticism for being too good at sport, considering that sport is hypermasculine and is often characterized by maledominant attributes such as strength, aggression, and stoicism (Hickey, 2008) . This gendered stereotyping has been suggested to have serious negative effects, particularly for girls (Coakley \& White, 1992). Similar to the findings of $\mathrm{Vu}$ et al. (2006), gendered stereotyping and teasing was a primary negative factor for adolescent girls and could potentially result in a lower preference for physical activities and a higher preference for isolative and sedentary activities, both now and in the future.

Teachers and coaches also influenced motivation to participate in sport and physical activity through positive feedback and role modeling. A negative climate, however, was created when teachers or coaches inadvertently gave feedback that was interpreted as a negative message. Research has shown that the way in which adults give feedback can influence a child's interpretation of performance success their and future motivation (Biddle, Hanrahan, \& Sellars, 2001). Within the school environment, Wright (1997) found very different social realities and learning environments in single-sex as well as coeducational classes for boys and girls: "Boys are positioned centrally in relation to the discourses of physical education which privilege the knowledge and values associated with the dominantly masculine practice of traditional team games; girls are positioned and position themselves as marginal, in need of constant encouragement, cajoling and detailed instruction" (p. 69). Furthermore, Wright found that during a team game, within the context of physical education, the lesson seemed to only highlight skill differences between boys and girls, and that girls seemed to receive more negative statements or commands compared to boys (e.g., "Bad luck;" "Out;" "It's not going to come to you if you don't chase the ball"). It is important, therefore, that teachers and coaches assess and monitor their feedback as well as the lesson content (Wright, 1997), as this is particularly critical when engaging adolescent girls in sports and physical activities.

Motivation to participate in sport and physical activity was also hampered by the school and sportclub setting. Participants reported that the structure of sports and physical education in their schools and communities was not always conducive to participation in physical activities because of their competitive nature. Again, within the school environment this was compounded by the coeducational structure of physical educational classes, where boys were too rough and often excluded girls from activities, as well as circumstances in which classes were instructed by male teachers who were perceived to lack understanding of the girls' needs. Similarly, Wright (1997) found that during a Grade 7 coeducational basic skill lesson that included a modified sports game, girls avoided contact with the ball to avoid being tackled by other players, and they attempted to avoid hitting the ball for fear of failing to hit the ball, being "out" in front of the class, or letting their team down. These girls were then increasingly identified as a "problem" because of their reluctance to participate. Physical education has been viewed as a traditionally masculine area of the curriculum (Epstein, Kehily, Mac an Ghaill, \& Redman, 2001; Paechter, 2003), and tends to be dominated by competitive lesson content. The hypermasculine space in the physical education curriculum privileges those who are competent in sport and marginalizes those with less skill (Hickey, 2008). In the context of school physical education, girls appear to receive an equal opportunity to participate; however, they are often considered less skilled, less physically able, and less interested (Scraton, 1993). 
In this way, sport and physical education can become exclusive, whereby those considered skilled, physically able, and interested thrive on opportunities to practice their skills, and in doing so have more opportunity to enhance their motor skill proficiency and therefore competency (Castelli \& Erwin, 2007).

The findings of this study suggest that the gendered social and organizational environment supported the adolescent girls to make social comparisons of their physical activity performance with their peers, and did not support them to develop and focus on selfreferenced standards. Social comparison usually involves a child focusing on comparing their performance to others, rather than adopting autonomous achievement strategies whereby a person can decipher when it is appropriate to compare to others or adopt self-referenced standards (Weinberg \& Gould, 2003). Developing self-referenced standards might be important considering that an individual's perception of his or her sporting ability, the value he or she places on being good at sports, and the degree to which an individual believes he or she is capable of succeeding at a task have shown to be powerful predictors of physical activity behavior (Eccles \& Harold, 1991; Kremer \& Busby, 1998). Considering that adolescence is a time to develop lifelong skills, promoting self-referencing standards is important for increasing participation in sport and physical activity among adolescent girls.

One strategy that some girls adopted in this study to maintain their participation in physical activity, despite their lack of motor skill proficiency, was to choose nontraditional sports or sports that did not assume gendered stereotypes. The girls considered participating in sports such as football (soccer) rather than netball because there was a greater chance of gaining a position on the team, and less chance that attention would be drawn to their motor skill proficiency. Netball is a traditional sport among Australian girls and women. In the regional context, adolescent girls who perceived that they did not have a high level of motor skill proficiency in netball were more likely to withdraw from participation. The availability of nontraditional sports is a strategy to deflect attention away from a lack of motor skill proficiency and competency, thereby increasing and/or maintaining regular participation in physical activities by adolescent girls.

Parents were reported to influence motivation to participate in sport or physical activity. Indirectly, they provided a positive climate for participation by modeling their behavior. Parental activity has been shown to be a determinant of physical activity levels in children, as parents model physical activity behavior for their children, provide social support, or provide access to sports and physical activities (Dempsey, Kimiecik, \& Horn, 1993; Dwyer et al., 2006; Kalakanis et al., 2001). Parents who are physically active or members of sporting clubs might be even more influential in a rural context, considering that there are limited opportunities in rural communities for sports and recreation; these opportunities are often difficult to access because of their remoteness (e.g., $50 \mathrm{kms}$ to $100 \mathrm{kms}$ ), and parents need to be willing and able to provide transport. The provision of sport and recreation opportunities for all members of a family might be even more important in rural communities for supporting adolescent girls' physical activity behaviors.

In considering the findings there are several limitations that must be acknowledged. The recruitment of the sample was limited to four schools in rural Victoria. There was a tendency for active girls to accept the invitation to participate in the focus group discussions; nevertheless, there were a small number of girls who reported participating in more passive activities. Those girls who were active were comfortable discussing their perceptions of their inactive peers. The findings of this study might also be limited by the respondents' tendency to provide socially desirable responses. The authors attempted to reduce this bias by informing participants that there were no right or wrong answers, and that everything discussed in the focus group was confidential and should not be shared with anyone outside the group. The findings of this study cannot be generalized to the broader population; however, the qualitative nature of the study supports and extends many of the findings that have been previously reported in the literature.

The unique findings of this research highlight that perceived self-competence is a major influence on Grade 7 girls' participation, and that there are a range of gendered social and organizational factors that influence this. This is one of the first studies to examine independent and interacting factors that influence sport and physical activity behavior of adolescent girls in a rural context. Future research could investigate the influence of the gendered social and organizational environment on perceived self-competence on a much larger scale, and specifically explore how intrapersonal, interpersonal, organizational, and environmental factors affect enjoyment, happiness, anxiety, pride, 
or shame. There has been an attempt to build tolerance, equity, and responsibility through physical education and sport programs; however, Hickey (2008) suggests that their availability and impact have been very localized, and one of the greatest challenges to increasing participation in sports is developing approaches to nurturing social cohesion within schools and the wider community. Therefore, gender should be explored as a central theme to the socioecological model of health, and research needs to explore the most effective strategies for addressing both boys' behavior and teaching practices regarding girls' participation in sport and physical activity (Hickey, 2008; Vu et al., 2006). Research is also needed to increase understanding of the relationship between physical activity levels, sports, and family involvement in the rural context.

To promote participation in sport and physical activity, practitioners, policy makers, and physical education teachers need to focus on developmentally appropriate activities that are fun, providing opportunities for singlesex classes, and generating cultural changes that encourage noncompetitive and self-referencing activities. In practice, adolescents need to be encouraged to resist making comparisons between themselves and the efforts and achievements of their peers, and a broad range of physical activities need to be emphasized to ensure a balance between competitive and self-referencing activities (Garrett \& Wrench, 2005). It is also suggested that this approach involve adolescent girls in the decisionmaking process, to give them a choice, and to strengthen feelings of empowerment to develop skills for lifelong participation in sports or physical activities (Brooks \& Magnusson, 2006).

\section{References}

Allender, S., Cowburn, G., \& Foster, C. (2006). Understanding participation in sport and physical activity among children and adults: A review of qualitative studies. Health Education Research, 21(6), 826-835.

Allison, K., Dwyer, J., \& Makin, S. (1999). Perceived barriers to physical activity among high school students. Preventive Medicine, 28, 608-615.

Australian Bureau of Statistics. (2006). 2006 census data by location. Canberra, Australia: Author. Retrieved April 23, 2008, from http://www.censusdata.abs.gov.au/ABSNavigation/ prenav/PopularAreas? $\&$ collection $=$ Census $\&$ period $=2006 \& \&$ navmapdisplayed $=$ true $\&$ javascript $=$ true $\&$ textversion $=$ false

Australian Bureau of Statistics. (2008). Census of population and housing: Socio-economic indexes for areas (SEIFA) Technical paper, 2006 (No.2039.0.55.001). Canberra, Australia: Author.
Australian Institute of Health and Welfare. (2003). Australia's young people 2003: Their health and wellbeing (AIHW cat. no. PHE 50). Canberra, Australia: Author.

Australian Institute of Health and Welfare. (2004). Rural, regional and remote health: A guide to remoteness classifications (AIHW Catalogue Number PHE 53). Canberra, Australia: Author.

Bauer, K. K., Yang, Y. W., \& Austin, S. B. (2004). "How can we stay healthy when you're throwing all of this in front of us?" Findings from focus groups and interviews in middle schools on environmental influences on nutrition and physical activity. Health Education and Behavior, 31(1), 34-46.

Biddle, S., Hanrahan, S., \& Sellars, C. (2001). Attributions: Past, present, and future. In R. Singer, H. Hausenblas, \& C. Janelle (Eds.), Handbook of sport psychology (2nd ed., pp. 444-471). New York: Wiley.

Bogdan, R., \& Biklen, S. (1992). Qualitative research for education: An introduction to theory and methods (2nd ed.). Boston: Allyn and Bacon.

Brady, F. (2004). Children's organized sports: A developmental perspective. Journal of Physical Education, Recreation and Dance, 75(2), 35.

Brooks, F., \& Magnusson, J. (2006). Taking part counts: Adolescents' experiences of the transition from inactivity to active participation in school-based physical education. Health Education Research, 21(6), 872-883.

Burns, S., Maycock, B., Cross, D., \& Brown, G. (2008). The power of peers: Why some students bully others to conform. Qualitative Health Research, 18, 1704-1716.

Cash, T. (1995). Developmental teasing about physical appearance: Retrospective descriptions and relationship with body image. Social Behavior Perspective, 23, 123-130.

Castelli, D., \& Erwin, H. (2007). Chapter 4: A comparison of personal attributes and experiences among physically active and inactive children. Journal of Teaching in Physical Education, 26, 375-389.

Coakley, J., \& White, A. (1992). Making decisions: Gender and sport participation among British adolescents. Sociology of Sport Journal, 9(1), 20-35.

Dempsey, J. M., Kimiecik, J. C., \& Horn, T. S. (1993). Parental influence on children's moderate to vigorous physical activity participation: An expectancy-value approach. Pediatric Exercise Science, 5, 151-167.

Department of Planning and Community Development. (2008). Find your local council. Retrieved March 19, 2008, from http:/www.localgovernment.vic.gov.au/web20/dvclgv.nsf/ headingpagesdisplay/find+your+local+council

Dixon, J., \& Welch, N. (2000). Researching the rural-metropolitan health differential using the "social determinants of health." Australian Journal of Rural Health, 8(5), 254-260.

Duncan, M., Spence, J., \& Mummery, K. (2005). Perceived environment and physical activity: A meta-analysis of selected environmental characteristics. International Journal of Behavioral Nutrition and Physical Activity, 2(11), 1-9.

Dwyer, J., Allison, K., Goldenberg, E., Fein, A., Yoshida, K., \& Boutilier, M. (2006). Adolescent girls' perceived barriers to participation in physical activity. Adolescence, 41(161), 75-89.

Eccles, J., \& Harold, R. (1991). Gender differences in sport involvement: Applying the Eccles' Expectancy-Value Model. Journal of Applied Sport Psychology, 3, 7-35. 
Eccles, J., Midgley, C., Wigfield, A., \& Buchanan, C. (1993). Development during adolescence: The impact of stage/ environment fit. American Psychologist, 48, 90-101.

Eime, R., Payne, W., Casey, M., \& Harvey, J. (in press). Transition in participation in sport and unstructured physical activity for rural living adolescent girls. Health Education Research, Advance access published on November 27, 2008; doi:10.1093/ her/cyn060.

Ennis, C. (1996). Students' experiences in sport-based physical education: More than apologies are necessary. Quest, 48, 453-456.

Epstein, D., Kehily, M., Mac an Ghaill, M., \& Redman, P. (2001). Boys and girls come out to play: Making masculinities and femininities in school playgrounds. Men and Masculinities, 4(2), 158-172.

Faith, M., Leone, M., Ayers, T., Heo, M., \& Pietrobelli, A. (2002). Weight criticism during physical activity, coping skills, and reported physical activity in children. Pediatrics, 110, 1-8.

Garcia, A., Broda, M., Frenn, M., Coviak, C., Pender, N., \& Ronis, D. (1995). Gender and developmental differences in exercise beliefs among youth and prediction of their exercise behavior. Journal of School Health, 65(5), 213-219.

Garcia, A., Pender, N., Antonakos, C., \& Ronis, D. (1998). Changes in physical activity beliefs and behaviors of boys and girls across the transition to junior high school. Journal of Adolescent Health, 22, 394-402.

Garrett, R., \& Wrench, A. (2005). "They should talk to us." Inclusivity and physical education. Teaching health and physical education in Australian primary schools. Retrieved October 3, 2008, from http://espace.library.uq.edu.au/view/ UQ:9758

Giles-Corti, B., \& Donovan, R. J. (2002). Socioeconomic status differences in recreational physical activity levels and real and perceived access to a supportive physical environment. Preventive Medicine, 35(6), 601-611.

Gordon-Larsen, P., Nelson, M., Page, P., \& Popkin, B. (2006). Inequality in the built environment underlies key health disparities in physical activity and obesity. Pediatrics, 117, 417-424.

Hallal, P., Victoria, C., Azevedo, M., \& Wells, J. (2006). Adolescent physical activity and health: A systematic review. Sports Medicine, 36(12), 1019-1030.

Harris, J. (1993). Young people's perceptions of health, fitness and exercise. British Journal of Physical Education Research Supplement, 13, 5-9.

Hickey, C. (2008). Physical education, sport and hyper-masculinity in schools. Sport, Education and Society, 13(2), 147-161.

Holt, N. L., Moylan, B. A., Spence, J. C., Lenk, J. M., Sehn, Z. L., \& Ball, G. D. C. (2008). Treatment preferences of overweight youth and their parents in Western Canada. Qualitative Health Research, 18, 1206-1219.

Humbert, L., Chad, K., Bruner, M., Spink, K., Muhajarine, N., Anderson, K., et al. (2008). Using naturalistic ecological approach to examine the factors influencing youth physical activity across grades 7 to 12 . Health Education and Behavior, 35(2), 158-173.

Humbert, M., Chad, K., Spink, K., Muhajarine, N., Anderson, K., Bruner, M., et al. (2006). Factors that influence physical activity participation among high- and low-SES youth. Qualitative Health Research, 16, 467-483.
Kalakanis, L., Goldfield, G., Paluch, R., \& Epstein, L. (2001). Parental activity as a determinant of activity level and patterns of activity in obese children. Research Quarterly for Exercise and Sport, 72(3), 243-252.

Kientzler, A. (1999). Fifth and seventh grade girls' decisions about participation in physical activity. Elementary School Journal, 99(5), 391-414.

Kremer, J., \& Busby, G. (1998). Modelling participation motivation in sport and exercise: An integrative approach. Irish Journal of Psychology, 19(4), 447-463.

Lubans, D., Sylva, K., \& Morgan, P. (2007). Factors associated with physical activity in a sample of British secondary school students. Australian Journal of Educational and Developmental Psychology, 7, 22-30.

Martin, S., Kirkner, G., Mayo, K., Matthews, C., Durstine, J., \& Hebert, J. (2005). Urban, rural, and regional variations in physical activity. Journal of Rural Health, 21(3), 239-244.

McLeroy, K., Bibeau, D., Steckler, A., \& Glanz, K. (1988). An ecological perspective on health promotion programs. Health Education Quarterly, 15(4), 351-377.

Miles, M., \& Huberman, M. (1994). Qualitative data analysis (2nd ed.). Thousand Oaks, CA: Sage.

Mooney, A., Creeser, R., \& Blatchford, P. (1991). Children's view on teasing and fighting in junior high school. Education Research, 33, 103-112.

Norton, E. C., Lindrooth, R. C., \& Ennet, S. T. (1998). Controlling for the endogeneity of peer substance use on adolescent alcohol and tobacco use. Health Economics, 7, 439-453.

Paechter, C. (2003). Masculinities and femininities as communities of practice. Women's Studies International Forum, 26(1), 69-77.

Parks, S. E., Housemann, R. A., \& Brownson, R. C. (2003). Differential correlates of physical activity in urban and rural adults of various socioeconomic backgrounds in the United States. Journal of Epidemiology and Community Health, 57(1), 29-35.

Pate, R., Dowda, M., O’Neill, J., \& Ward, D. (2007). Change in physical activity participation among adolescent girls from 8th to 12 grade. Journal of Physical Activity and Health, 4, 3-16.

Perkins, D., Jacobs, J., Barber, B., \& Eccles, J. (2004). Childhood and adolescent sports participation as predictors of participation in sports and physical fitness activities during young adulthood. Youth and Society, 35, 495-518.

QSR International. (2007). NVivo Version 7. [Computer Software]. Retrieved October 1, 2007, from http://www.qsrinternational .com

Sallis, J., \& Owen, N. (2002). Ecological models of health behavior. In K. Glanz, B. Rimer, \& F. Lewis (Eds.), Health behavior and health education: Theory, research, and practice (3rd ed., pp. 462-485). San Francisco: Jossey-Bass.

Sanchez, A., Norman, G., Sallis, J., Calfas, K., Cella, J., \& Patrick, K. (2007). Patterns and correlates of physical activity and nutrition behaviors in adolescents. American Journal of Preventive Medicine, 32(2), 124-130.

Scheerder, J., Vanreusel, B., Taks, M., \& Renson, R. (2005). Social stratification patterns in adolescents' active sports participation behaviour: A time trend analysis 1969-1999. European Physical Education Review, 11(5), 5-27.

Schulenberg, J., Maggs, J., \& Hurrelmann, K. (1997). Negotiating developmental transitions during adolescence and young 
adulthood: Health risks and opportunities. In J. Schulenberg, J. L. Maggs, \& K. Hurrelmann (Eds.), Health risks and developmental transitions during adolescence (pp. 1-19). Cambridge, UK: Cambridge University Press.

Scraton, S. (1993). Equality, coeducation and physical education in secondary schooling. In J. Evans (Ed.), Equality, education and physical education (pp. 139-153). London: Falmer Press.

Shapiro, J., Baumeister, R., \& Kessler, J. (1991). A three-component model of children's teasing: Aggression, humor, and ambiguity. Journal of Social and Clinical Psychology 10, 459-472.

Sleap, M., \& Wormald, H. (2001). Perceptions of physical activity among young women aged 16 and 17 years. European Journal of Physical Education, 6, 26-37.

Sparling, P. B., Owen, N., Lambert, E. V., \& Haskell, W. L. (2000). Promoting physical activity: The new imperative for public health. Health Education Research, 15(3), 367-376.

Stewart, C., \& Taylor, J. (2000). Why female athletes quit: Implications for coach education. Physical Educator, 57(4), 170

Taylor, T., Legrand, N., \& Newton, J. (1999). Myth and reality: Exploring teenage schoolgirl sport participation. Journal of the International Council for Health, Physical Education, Recreation, Sport, and Dance, 35, 32-36.

Thompson, A. M., Humbert, M. L., \& Mirwald, R. L. (2003). A longitudinal study of the impact of childhood and adolescent physical activity experiences on adult physical activity perceptions and behaviors. Qualitative Health Research, 13, 358-377.

Thompson, J., Cattarin, J., Fowler, B., \& Fisher, E. (1995). The Perception of Teasing Scale (POTS): A revision and extension of the Physical Appearance-Related Teasing Scale (PARTS). Journal of Personality Assessment, 65, 146-157.

Trew, K., Scully, D., Kremer, J., \& Ogle, S. (1999). Sport, leisure and perceived self-competence among male and female adolescents. European Physical Education Review, 5(1), 53-73.

Vilhjalmsson, R., \& Kristjansdottir, G. (2003). Gender differences in physical activity in older children and adolescents: The central role of organized sport. Social Science and Medicine, $56,363-374$.
Vu, M., Murrie, D., Gonzalez, V., \& Jobe, J. (2006). Listening to girls and boys talk about girls' physical activity behaviors. Health Education and Behavior, 33(1), 81-96.

Warburton, D., Nicol, C., \& Bedin, S. (2006). Health benefits of physical activity: The evidence. Canadian Medical Association Journal, 174(6), 801-809.

Weinberg, R., \& Gould, D. (2003). Foundations of sport and exercise psychology (3rd ed.). Adelaide, Australia: Human Kinetics.

Weiss, M. (1993). Psychological effects of intensive sport participation on children and youth: Self-esteem and motivation. In B. R. Cahill \& A. J. Pearl (Eds.), Intensive participation in children's sports (pp. 39-69). Champaign, IL: Human Kinetics.

Weiss, M., \& Chaumeton, N. (1992). Motivational orientations in sport. In T. Horn (Ed.), Advances in sport psychology (pp. 61-99). Champaign, IL: Human Kinetics.

Wong, E. H. (1995). A model of motivational orientation for youth sport: Some preliminary work. Adolescence, 30, 437-452.

Wright, J. (1997). The construction of gendered contexts in single sex and co-educational physical education lessons. Sport, Education and Society, 2(1), 55-72.

Zick, C., Smith, K., Brown, B., Fan, J., \& Kowaleski-Jones, L. (2007). Physical activity during the transition from adolescence to adulthood. Journal of Physical Activity and Health, 4, 125-137.

Meghan Casey, BApSci(Hons), is a doctoral candidate in the School of Human Movement and Sport Sciences at the University of Ballarat in Mt. Helen, Victoria, Australia.

Rochelle Eime, $\mathrm{PhD}$, is a research fellow in the School of Human Movement and Sport Sciences at the University of Ballarat in Mt. Helen, Victoria, Australia.

Warren Payne, $\mathrm{PhD}$, is a professor in the School of Human Movement and Sport Sciences at the University of Ballarat in Mt. Helen, Victoria, Australia.

Jack Harvey, $\mathrm{PhD}$, is a senior research fellow in the School of Human Movement and Sport Sciences at the University of Ballarat in Mt. Helen, Victoria, Australia.

For reprints and permissions queries, please visit SAGE's Web site at http://www.sagepub.com/journalspermissions.nav. 